\title{
Fungal Derived Biosynthesised Silver Nanoparticles: a New Approach for Root Canal Disinfection- a Review
}

\author{
Rahul Halkai ${ }^{1(\mathbb{D})}$, Kiran. R. Halkai ${ }^{2, *}{ }^{(\mathbb{D})}$, Swapna Munaga ${ }^{3(\mathbb{D})}$, RajKiran Chitumalla ${ }^{3(\mathbb{D})}$, \\ Shishir Ram Shetty ${ }^{4}$, Jyothi C. 5 (i)

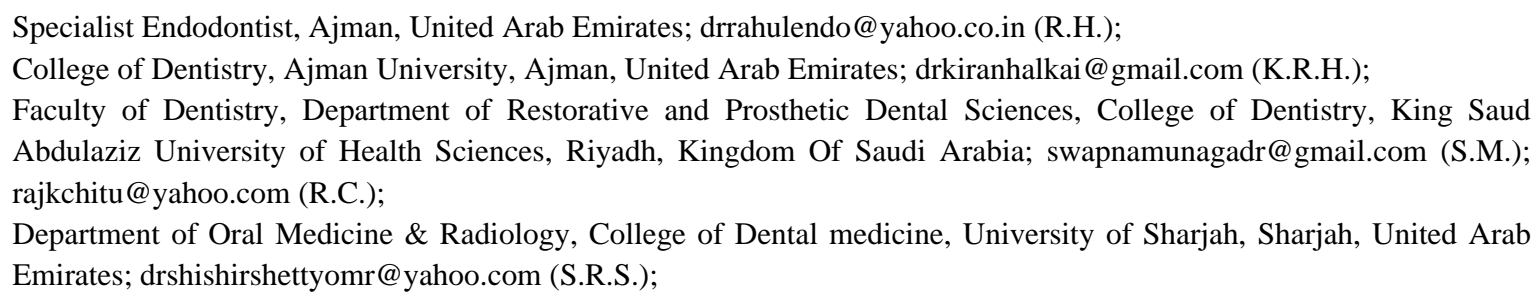
Emirates; drshishirshettyomr@yahoo.com (S.R.S.); \\ 4 Department of Oral Medicine \& Radiology, College of Dental medicine, University of Sharjah, Sharjah, United Arab \\ 5 Department of Periodontics, Oxford Dental College\& Hospital, Bengaluru, India; drcjyothi@gmail.com (J.C.); \\ * Correspondence: drkiranhalkai@gmail.com;
}

Received: 15.07.2020; Revised: 14.08.2020; Accepted: 16.08.2020; Published: 19.08.2020

\begin{abstract}
Complex root canal morphology, biofilm mediated endodontic infection, and growing microbial resistance to conventional root canal disinfectants lead to endodontic failures. Hence there is an ongoing search for new antimicrobial agents for root canal disinfection. Several nanoparticles were used for root canal disinfection; however, in recent days, biosynthesized silver nanoparticles (AgNPs) have gained immense interest due to their unique properties. Hence, biosynthesized AgNPs provide a new horizon for root canal disinfection due to effective antimicrobial activity and biocompatibility. This review article focuses on the biosynthesis of AgNPs using fungi and their application as antimicrobial agents in root canal disinfection.
\end{abstract}

Keywords: Biosynthesis; fungi; biosynthesized silver nanoparticles; antimicrobial agents; root canal disinfection.

(C) 2020 by the authors. This article is an open-access article distributed under the terms and conditions of the Creative Commons Attribution (CC BY) license (https://creativecommons.org/licenses/by/4.0/).

\section{Introduction}

The main causative factors for root canal infection are the microorganisms [1]. Even after rapid development in endodontic practice, we encounter failures either due to persistent infection or reinfection; therefore, the goal of the root canal treatment is to achieve a complete microbial free environment [2]. It is a known fact that along with mechanical preparation, root canal irrigation and intracanal medicaments are essential for endodontic disinfection [3,4]. However, complex root canal morphology, adverse effects, and limitations of conventional root canal disinfectants and growing bacterial resistance to available antimicrobial agents pose a challenge for thorough root canal disinfectant [5].

Antimicrobial agents are commonly employed for root canal disinfection as irrigants and intracanal medicaments (ICMs); hence, their role is critical in endodontic treatment outcome [2]. Root canal irrigants play a key role as they penetrate the root canal irregularities, dentinal tubules, ramifications, fins, isthmus, etc., where instruments cannot reach [6]. The most commonly used endodontic irrigants are sodium hypochlorite $(\mathrm{NaOCl})$, ethylene- 
diamine-tetra-acetic acid (EDTA) solution, and a chlorhexidine (CHX) [7,8]. The disadvantages with $\mathrm{NaOCl}$ include limited penetrability in the complex root canal system, toxicity, risk of emphysema, allergy, offensive smell, taste, and also its inability to remove the smear layer[9]. Chlorhexidine ( $\mathrm{CHX}$ ) has been used effectively as an alternative to $\mathrm{NaOCl}$ for root canal irrigation due to its broad-spectrum antimicrobial activity and substantivity effect on root dentine. However, the disadvantages include discoloration of the tooth, can cause dryness and burning sensation in oral mucosa, and forms brown precipitate upon interaction with $\mathrm{NaOCl}[10]$. Chelating agents such as $17 \%$ ethylenediaminetetraacetic acid (EDTA), $10 \%$ citric acid, tannin, and maleic acid are used for smear layer removal [11,12]. However, irrigation with EDTA could demineralize the dentine and produce erosions in coronal as well as the middle part of the root canal system, and it does not remove the organic debris [13]. Therefore, antimicrobial agents with effective antimicrobial activity without drug resistance and improved properties have to be developed [14].

Nanoparticles(NPs) have emerged as newer antimicrobial agents for root canal disinfection due to their unique properties such as smaller size in the range of 1-100 nm, high surface area; also, they can penetrate deeper into tissues at much smaller doses and biocompatibility [15]. Drug resistance has not been reported against NPs till now, as it needs several genetic mutations to occur, which need a long time for the microorganisms to overcome this [16]. Synthetic nanoparticles such as chitosan, zinc oxide nanoparticles, and AgNPs, etc., have been studied as root canal irrigants and ICMs with promising antimicrobial efficacy [1719].

Recently, nanotechnology has shifted to biological approaches due to the concern regarding various chemicals used during processing and causing health hazards to human health and the environment. The synthetic process for producing nanoparticles is very expensive, technical difficulty, and tedious process. On the other hand, biological approaches for the production of NPs, using natural entities like fungi, bacteria, viruses, leaf extract, bark, etc., are economical, and no toxic chemicals are used in the process, much effective and biocompatible [20]. Several nanoparticles, such as silver, gold, copper, zinc, etc., are produced by biological approaches. Silver nanoparticles (AgNPs) exhibit potential antimicrobial activity against various microorganisms and are biocompatible [2]. Fungi have more advantages compared to other microorganisms for AgNPs synthesis such as: can be easily grown with simple media on a large scale, economic, fast, secrete a large amount of bioactive substances, enzymes such as nitrate reductase which act as reducing agents, possess high wall binding capabilities acting as stabilizing and capping agents hence, considered as naturally occurring nano factories $[2,21]$. The present study aims to review the biosynthesis of AgNPs using fungi and their role in root canal disinfection.

\section{Methodology for search}

\subsection{Search strategy.}

Studies were identified through a search using the following electronic databases: PubMed, Web of Science, Scopus, Google Scholar, and Cochrane database of systematic reviews. The following terms were used as keywords: biosynthesized / green synthesized silver nanoparticles, fungal derived, silver nanoparticles, root canal failure, root canal disinfectants, endodontic pathogens, and antimicrobial activity and combination of these keywords. The literature was reviewed from January 1990- June 2020. 


\subsection{Study selection.}

According to selection criteria, studies were required to (a) be published in peerreviewed journals in the English language only (b) provide original data, and (c) explicitly report on the antimicrobial efficacy of biosynthesized silver nanoparticles against endodontic pathogens or their role in root canal disinfection. Articles published as abstracts only, thesis work, and other languages were excluded. The search results are summarized, as mentioned below.

\section{Bio-based methods for AgNP synthesis}

According to most of the studies, NPs produced by synthetic processes using chemical approaches cause hazards to human health and the environment. Thus, there is a growing need to develop eco-friendly processes that are economical and do not use toxic chemicals in the process [20]. This led to the search of natural entities such as microorganisms, which include bacteria, viruses, fungi, and herbal extracts, etc., which can be used to produce NP's due to their biological properties. The potential microorganisms capable of producing NPs range from simple prokaryotic bacterial cells to eukaryotic fungi and plants. The biological entities can reduce the bulk metallic compounds and produce NPs [15].

Highly stable NPs are produced if certain critical aspects have been considered, such as types of microorganisms, their genetic properties, optimal conditions for cell growth, and enzyme activity. The size and shape of the NPs can be controlled by altering substrate concentration, $\mathrm{pH}$, light, temperature, buffer strength, electron donor, biomass and substrate concentration, mixing speed, and exposure time [22].

\section{Fungal derived silver nanoparticles}

\subsection{Biosynthesis of AgNPs using fungi.}

The process of biosynthesis of AgNPs using fungi is same as any other natural entities, such as isolation of microorganisms from different sources such as leaves of some plants, soil samples, bark, and roots, etc., and need to be cultured and grown depending upon the growth requirements $[2,20]$. Once grown, the fungi are isolated and sub-cultured. The fungal isolate is then added to any suitable liquid growth media and cultured until lavish fungal biomass is obtained, usually within 3-4 days. The biomass is washed several times and placed in distilled water for another 24-48 hrs and filtered; the obtained filtrate without biomass is used further [2]. Usually, $1 \mathrm{mmol}$ concentration of aqueous silver nitrate $\left(\mathrm{AgNO}_{3}\right)$ solution is added to the filtrate. If other NPs are to be produced, any other suitable ion solution such as silver sulfate, etc., are used instead of $\mathrm{AgNO}_{3}$ and monitored for NPs formation. Another technique includes the direct addition of the fungal hyphae to the ion solution instead of fungal filtrate [2]. The biological reaction includes the reduction of ions in solution by fungal derived enzymes and AgNPs, thus formed were stabilized by capping peptides [23]. The reaction can be observed by visual observation of color change of the solution, which turns to dark brown color or the hyphae become dark in color, indicating the formation of AgNPs [2]. The color change after addition of $\mathrm{AgNO}_{3}$ to fungal filtrate is due to excitation of surface plasmon vibrations essentially the vibrations of the group conduction electrons in the AgNPs and increase in color intensity of culture filtrate occurs due to increased number of nanoparticles produced as a result of reduction of silver ions $[24,25]$. Several studies were reported using various fungi for the 
biosynthesis of AgNPs. Stable AgNPs were synthesized extracellularly using Fusarium oxysporum. The long-term stability of the nanoparticle solution might be due to the stabilization of the AgNPs by fungal derived proteins [26]. AgNPs have been reported to interact strongly with proteins, including cytochrome $c(\mathrm{Cc})$ [27]. In Fusarium oxysporum, the bioreduction of silver ions occurs due to an enzymatic process involving NADH-dependent reductase [28]. The secreted enzyme nitrate reductase was found to be dependent on NADH cofactor, and it is responsible for the formation of AgNPs in solution [29]. The high stability of NPs in solution was due to the release of capping proteins by $F$. oxysporum, which act as capping agents. It is shown that the NPs in solution remained stable at higher $\mathrm{pH}$ values $(>12)$, and they aggregated at lower $\mathrm{pH}$ values $(<2)$ as the protein was denatured; hence the stability of the capping protein was found to be $\mathrm{pH}$-dependent [22].

Kumar et al., demonstrated in vitro biosynthesis of AgNPs using $\alpha$-NADPH-dependent nitrate reductase enzyme purified from $F$. oxysporum and Phytochelatin. The advantages of this protocol have led to the development of a new approach for the biosynthesis of NPs over a range of chemical compositions and shapes without possible aggregation and also eliminates the downstream processing required for the use of these NPs in homogeneous catalysis and other applications such as non-linear optics [29]. Mukherjee et al. proposed a novel biological method using Vericillum sp. for AgNps synthesis using a two-step mechanism. The first step includes the trapping of the silver ions at the surface of the fungal cells. In the second step, the enzymes present in the fungal cell reduce silver ions, therefore forming AgNPs [30].

AgNPs were green synthesized using Aspergillus flavus, and the particles were found to be stable more than 3 months with no significant aggregation because of surface binding of stabilizing substances secreted by the fungus [31]. Extracellular biosynthesis of AgNPs was reported using Aspergillus fumigatus and Cladosporium cladosporioides biomass [32,33]. It was suggested that proteins, organic acids, and polysaccharides released by $C$. cladosporioides were responsible for the formation of spherical crystalline silver NPs [33]. Endophytic fungi such as Fusarium semitectum was found to be effective in producing stable AgNPs [34]. Endophytic fungi live inside the internal tissues of plants and do not cause any side effects. The potential advantages are they are rich sources of bioactive secondary metabolites with unique structures for the production of AgNPs [35,36].

\subsection{Characterization.}

Characterization of AgNPs is essential for better understanding the morphology, size, shape, presence of biomolecules, characteristics, and for confirmation of the formation of AgNPs $[2,21]$. The basic characterization techniques include visual observation showing color change which can be attributed to the enzymatic reduction of silver ions when exposed to the fungi and this leads to change in the color of the solution, however, sometimes the solution remains clear, and only the fungal hyphae changes /darkens the color in solution [2]. UV Spectrum shows the absorbance peak in the range of 380-450nm due to the excitation of surface Plasmon resonance of AgNPs [20]. Scanning electron microscope (SEM) and high-resolution Transmission electron microscope (TEM) allows us to ascertain the size, shape, morphology, and aggregation level of AgNPs. The Selected Area Electron Diffraction (SAED) pattern of TEM allows confirming the crystalline nature of AgNPs [2,20]. Surface tomography, xeroradiography, and Fourier Transform Infrared Spectroscopy (FTIR) are some of the other commonly employed characterization techniques [20,21]. Extracellular biosynthesis of AgNPs employing the fungus Cladosporium cladosporioides was confirmed by UV-vis 
spectrophotometer, and the particles were found to be $10-100 \mathrm{~nm}$ in dimensions as measured by TEM images. The structure of AgNPs was analyzed using XRD technique and proteinAgNP interaction assessed by FTIR spectroscopy [34]. The presence of the bands in the FTIR spectra of AgNPs indicates that the secondary structure of the proteins is not affected during the formation of AgNPs or by the binding of the proteins with the AgNPs [35]. The presence of functional groups in the FTIR spectrum indicates the fungal derived proteins act as capping agents and stabilization of AgNPs [20]. In a study, AgNps were synthesized by both $C$. tropicum and F. oxysporum. The study concluded the size of $\mathrm{AgNps}$ increased as the $\mathrm{pH}$ of the ion solution decreased, and at a lower temperature, the nanoparticles were smaller in size while higher temperatures produced larger nanoparticles [37].

\section{Antimicrobial efficacy}

\subsection{Antimicrobial efficacy of fungal derived AgNPs against various pathogens.}

AgNPs were employed as antimicrobial agents against several pathogens like Grampositive, Gram-negative, MDR resistant strains and found to be effective even against tumor cells $[35,36,38]$. AgNPs were produced using fungus, Penicillium Sp isolated from healthy leaves of $C$. Longa (turmeric), characterized by visual observation, UV visible spectroscopy, Transmission Electron Microscopy (TEM) and Fourier Transform Infrared Spectroscopy (FTIR) and evaluated antibacterial activity against Escherichia coli, Pseudomonas aeruginosa, Klebsiella pneumoniae, Salmonella typhimurium, and Enterobacter aerogenes. The results showed that AgNPs had efficient antibacterial activity against $P$. aeruginosa, $K$. pneumoniae, with a maximum zone of inhibition of 21 and $15 \mathrm{~mm}$. The study concluded that endophytic fungi are rich sources of secondary metabolites, which can reduce metals producing AgNPs, and exhibit considerable antibacterial activity [35].

\subsection{Antimicrobial efficacy of fungal derived AgNPs against endodontic pathogens.}

Relatively very few studies show the antimicrobial efficacy of AgNPs against oral pathogens $[20,21]$. It is reported that biosynthesized AgNPs exhibit efficient antimicrobial activity against resistant bacteria, including E. faecalis with 12-16 mm zones of inhibition[39]. Antibiofilm efficacy of AgNPs was evaluated as a vehicle for calcium hydroxide medicament and shown to exhibited effective antibacterial activity against E. faecalis [40]. Similarly, Halkai

et al. showed effective antimicrobial efficacy against P.gingivitis, E.faecalis, and B.pumilus [20]. AgNPs were effective even against the biofilms of several resistant strains, such as $E$. faecalis [41]. Endo-perio lesions present a great clinical challenge due to the involvement of both the tissues, hence the use of AgNPs during treatment of these lesions will be beneficial in a successful outcome. It is shown that AgNPs exhibited effective antimicrobial activity against endo-perio pathogens both in planktonic and biofilm form in vitro models [42].

\section{Mechanism of antimicrobial activity}

The antimicrobial property of silver is defined by the release rate of silver ion. Silver in bulk status is considered an inert material. However, when it gets ionized by moisture, it will result in a highly reactive state. At this stage, silver can interact with bacterial cell walls leading to structural changes due to its binding to tissue protein [43]. Studies suggest that the antibacterial action of AgNPs includes the reaction between the positively charged AgNP 
molecules with the bacterial cell wall of negative charge leading to the damage of the bacteria cell wall [44]. In addition to being able to release silver ions, AgNPs may induce pits in the bacterial cell membrane and then get accumulated in the pits leading to fragmentation of the cell $[45,46]$. In addition to this, AgNPs can also penetrate bacterial cell walls and subsequently change the structure of the cell membrane which leads to the release of $\mathrm{Ag}$ ions, disruption of the cell wall and cellular contents, realize of reactive oxygen species (ROS), DNA damage and ultimately the cell death $[47,48]$.

AgNPs have a higher affinity for Gram-negative strains, which is due to the lower peptidoglycan content and narrower cell walls in Gram-negative bacteria. The thicker cell walls of Gram-positive bacteria inhibit the penetration of AgNPs into the cells [49]. The difference in affinity for bacteria is due to the ability of AgNPs for binding to the enzymes containing disulfide or sulfhydryl ( $\mathrm{SH}$ ) groups of enzymes that lead to disruption of metabolic processes, which in turn causes the cell death [50]. And it suggests that uptake of AgNPs is important to impart the antimicrobial effect on bacteria [51]. Other factors, such as the concentration, size, and shape of NPs, also affect the efficacy against the microorganisms [2]. Further, a decrease in the size of NPs increases antimicrobial efficacy due to increased surface area and biocompatibility; however, using AgNps in low concentrations can cause bacterial resistance [52].

Endodontic infection is biofilm mediated infection that poses the greatest difficulty for endodontic disinfection. It is shown that complete eradication of biofilm was not achieved with AgNPs, however, the same concentration has eradicated all of the planktonic bacteria [53]. The complicated structure and composition of the biofilm, diffusion rate, size, and shape, physicochemical characteristics of the AgNPs may determine its effect on biofilm [54]. The possible mechanism for biofilm inhibition to AgNPs may be attributed due to (1)Transport of AgNPs through biofilm can be greatly obstructed for particles larger than $50 \mathrm{~nm}$ (2) the chemical composition of nanoparticles can arouse adsorption and accumulation of silver nanoparticles in the biofilm, thereby reducing their diffusion (3) the electrostatic interaction between bacteria and AgNPs can influence charged nanoparticles penetration through the biofilm [55].

\section{Applications of AgNPs in endodontics}

AgNPs can be alternatively used to conventional irrigants for intracanal irrigation during endodontic treatment. Gutta-percha coated with AgNPs has been developed as an antimicrobial obturator for root canal obturation [56]. AgNPs are also incorporated as antibacterial material into mineral trioxide aggregate to enhance the success of pulp-capping, apexification, and sealing perforations in teeth [57]. Due to the unique properties and effective antimicrobial activity of biosynthesized AgNPs against the endodontic pathogens including the most resistant microbe E. faecalis, it has been recommended to incorporate AgNPs for root canal disinfection; they can be effectively used as root canal irritants, ICMs and can be combined with other ICMs for synergistic effects [2, 41].

However, several concerns need to be addressed for effective clinical use, such as discoloration of root dentin or the tooth, if it is used for root canal disinfection, any irritation to periapical tissues if it leaches, whether they can dissolve with contact to periapical tissues. It has been suggested that nanosilver particles slowly dissolve into a more toxic form, usually slowly with time[58]. However, studies show that fungal derived biomolecules act as stabilizing agents and prevent the dissolution of silver [35, 36]. 
Recently, the cytotoxicity of fungal derived biosynthesized AgNPs was evaluated on normal Human gingival fibroblast (HGF) cell line and found to be least cytotoxic, and a dose range below 256 micrograms was effective without causing any cytotoxicity [59]. However, literature is scarce in terms of in vivo studies. Therefore, further studies need to be conducted for the effective clinical use of these particles.

\section{Conclusion}

It is well anticipated that the application of nanoparticles has revolutionized clinical endodontic practice. The utilization of biosynthesized AgNPs for root canal disinfection is of considerable importance due to their eco-friendly and biological properties and pave a new horizon for endodontic practice as effective antimicrobial agents. This review showed an insight into the biosynthesis of AgNPs using fungi, properties, and mechanisms of antimicrobial activity and the effective use of these novel nanoparticulate systems to combat root canal infections. However, it is crucial to understand their shortcomings and their probable cellular effects. Therefore, further in vitro, in vivo studies and clinical trials are required to evaluate the efficacy of biosynthesized silver nanoparticles in reducing bacteria from the root canal system and effective use of these particles with the highest safety for patients.

\section{Funding}

This research received no external funding.

\section{Acknowledgments}

This research has no acknowledgment.

\section{Conflicts of Interest}

The authors declare no conflict of interest.

\section{References}

1. Onate Sanchez RE, Perez Diaz S, Rodriguez Lozano FJ, Guerrero Girones J, Prevalence of apical periodontitis in patients with multiple myeloma. Med Oral Patol Oral Cir Bucal 2020, 25, e383-e387, https://doi.org/10.4317/medoral.23416.

2. Halkai, K.; Mudda, J.; Shivanna, V.; Rathod, V.; Halkai, R. Biosynthesised Silver Nanoparticles from Fungi as Antimicrobial Agents for Endo-Perio Lesions - A Review. Annual Research \& Review in Biology 2016, 10, 1-7, https://doi.org/10.9734/ARRB/2016/25756.

3. Kishen, A. Advanced therapeutic options for endodontic biofilms. Endodontic Topics 2010, 22, 99-123, https://doi.org/10.1111/j.1601-1546.2012.00284.x.

4. Halkai, R.; Hegde, M.; Halkai, K. Evaluation of the presence of Enterococcus Faecalis in root cementum: A confocal laser scanning microscope analysis. J Conserv Dent. 2014, 17, 119-123, https://doi.org/10.4103/0972-0707.128039.

5. Dioguardi M, Alovisi M, Crincoli V et al. Prevalence of the Genus Propionibacterium in primary persistent endodontic lesions:A systematic review. J Clin Med,2020,9,739,http://doi.org/10.3390/jcm9030739

6. Haapasalo, M.; Endal, U.; Zandi, H.; Coil, J.M. Eradication of endodontic infection by instrumentation and irrigation solutions. Endodontic Topics 2005, 10, 77-102, https://doi.org/10.1111/j.16011546.2005.00135.x.

7. Ballal, N.V.; Kandian, S.; Mala, K.; Bhat, K.S.; Acharya, S. Comparison of the Efficacy of Maleic Acid and Ethylenediaminetetraacetic Acid in Smear Layer Removal from Instrumented Human Root Canal: A Scanning Electron Microscopic Study. Journal of Endodontics 2009, 35, 1573-1576, https://doi.org/10.1016/j.joen.2009.07.021. 
8. Verma D,Taneja S,Kumari M. Efficacy of different irrigation regimes on the push-out bond strength of various resin based sealers at different root levels: An invitro study. J Conserv Dent 2018, 21, 12529,https://doi.org/10.4103/ JCD.JCD_337_16.

9. Paula KB, Carlotto IB, Marconi DF, Ferreira MBC, Grecca FS,Montagner F. Calcium Hypochlorite solutions-An In vitro Evaluation of antimicrobial action and pulp dissolution. Eur Endod J 2019 ,4, 15-20, https://doi.org/10.14744/eej.2018.64936.

10. Basrani, B.R.; Manek, S.; Sodhi, R.N.S.; Fillery, E.; Manzur, A. Interaction between Sodium Hypochlorite and Chlorhexidine Gluconate. Journal of Endodontics 2007, 33, 966-969, https://doi.org/10.1016/j.joen.2007.04.001.

11. Lui, J.-N.; Kuah, H.-G.; Chen, N.-N. Effect of EDTA with and without Surfactants or Ultrasonics on Removal of Smear Layer. Journal of Endodontics 2007, 33, 472-475, https://doi.org/10.1016/j.joen.2006.12.007.

12. Gotze, G.d.R.; Cunha, C.B.C.S.; Primo, L.S.d.S.G.; Maia, L.C. Effect of the sodium hypochlorite and citric acid association on smear layer removal of primary molars. J Brazilian Oral Research 2005, 19, 261-266, https://doi.org/10.1590/s1806-83242005000400005.

13. Çalt, S.; Serper, A. Time-Dependent Effects of EDTA on Dentin Structures. Journal of Endodontics 2002 , 28, 17-19, https://doi.org/10.1097/00004770-200201000-00004.

14. Del Pozo, J.L.; Patel, R. The Challenge of Treating Biofilm-associated Bacterial Infections. Clinical Pharmacology \& Therapeutics 2007, 82, 204-209, https://doi.org/10.1038/sj.clpt.6100247.

15. Mohanpuria, P.; Rana, N.K.; Yadav, S.K. Biosynthesis of nanoparticles: technological concepts and future applications. Journal of Nanoparticle Research 2008, 10, 507-517, https://doi.org/10.1007/s11051-0079275-x.

16. Ansari, M.; Khan, H.; Khan, A.; Malik, A.; Sultan, A.; Shahid, M.; Shujatullah, F.; Azam, A. Evaluation of antibacterial activity of silver nanoparticles against MSSA and MRSA on isolates from skin infections. Biology and Medicine 2011, 3, 141-146.

17. Gomes-Filho, J.E.; Silva, F.O.; Watanabe, S.; Angelo Cintra, L.T.; Tendoro, K.V.; Dalto, L.G.; Pacanaro, S.V.; Lodi, C.S.; de Melo, F.F.F. Tissue Reaction to Silver Nanoparticles Dispersion as an Alternative Irrigating Solution. Journal of Endodontics 2010, 36, 1698-1702, https://doi.org/10.1016/j.joen.2010.07.007.

18. Shrestha, A.; Zhilong, S.; Gee, N.K.; Kishen, A. Nanoparticulates for Antibiofilm Treatment and Effect of Aging on Its Antibacterial Activity. Journal of Endodontics 2010, 36, 1030-1035, https://doi.org/10.1016/j.joen.2010.02.008.

19. Wu, D.; Fan, W.; Kishen, A.; Gutmann, J.L.; Fan, B. Evaluation of the Antibacterial Efficacy of Silver Nanoparticles against Enterococcus faecalis Biofilm. Journal of Endodontics 2014, 40, 285-290, https://doi.org/10.1016/j.joen.2013.08.022.

20. Halkai, K.R.; Mudda, J.A.; Shivanna, V.; Rathod, V.; Halkai, R.S. Biosynthesis, characterization and antibacterial efficacy of silver nanoparticles derived from endophytic fungi against. P. Gingivalis. J Clin Diagn Res 2017, 11, https://doi.org/10.7860/JCDR/2017/29434.10681.

21. Halkai, K.; Mudda, J.; Shivanna, V.; Rathod, V.; Halkai, R. Evaluation of antibacterial efficacy of biosynthesized silver nanoparticles derived from fungi against endo-perio pathogens Porphyromonas gingivalis, Bacillus pumilus, and Enterococcus faecalis. J Conserv Dent 2017, 20, 398-404, https://doi.org/10.4103/JCD.JCD_173_17.

22. Singh, D.; Rathod, V.; Ninganagouda, S.; Hiremath, J.; Singh, A.K.; Mathew, J. Optimization and Characterization of Silver Nanoparticle by Endophytic Fungi Penicillium sp. Isolated from Curcuma longa (Turmeric) and Application Studies against MDR E. coli and S. aureus. Bioinorganic Chemistry and Applications 2014, 2014, https://doi.org/10.1155/2014/408021.

23. Abbasi, E.; Milani, M.; Fekri Aval, S.; Kouhi, M.; Akbarzadeh, A.; Tayefi Nasrabadi, H.; Nikasa, P.; Joo, S.W.; Hanifehpour, Y.; Nejati-Koshki, K.; Samiei, M. Silver nanoparticles: Synthesis methods, bioapplications and properties. Critical Reviews in Microbiology 2016, 42, 173-180, https://doi.org/10.3109/1040841X.2014.912200.

24. Ahmed, A.A.; Hamzah, H.; Maaroof, M. Analyzing formation of silver nanoparticles from the filamentous fungus Fusarium oxysporum and their antimicrobial activity. Turkish journal of biology = Turk biyoloji dergisi 2018, 42, 54-62, https://doi.org/10.3906/biy-1710-2.

25. Vahabi, K.; Mansoori, A.G.; Karimi, S. Biosynthesis of silver Nanoparticle by fungus Trichoderma Reesi. Int Sciences J 2011, 1, 65-79, https://doi.org/10.5640/insc.010165.

26. Ahmad, A.; Mukherjee, P.; Senapati, S.; Mandal, D.; Khan, M.I.; Kumar, R.; Sastry, M. Extracellular biosynthesis of silver nanoparticles using the fungus Fusarium oxysporum. Colloids and Surfaces B: Biointerfaces 2003, 28, 313-318, https://doi.org/10.1016/S0927-7765(02)00174-1.

27. Macdonald, I.D.G.; Smith, W.E. Orientation of Cytochrome c Adsorbed on a Citrate-Reduced Silver Colloid Surface. Langmuir 1996, 12, 706-713, https://doi.org/10.1021/la950256w.

28. Ahmad, A.; Senapati, S.; Khan, M.I.; Kumar, R.; Ramani, R.; Srinivas, V.; Sastry, M. Intracellular synthesis of gold nanoparticles by a novel alkalotolerant actinomycete, Rhodococcusspecies. Nanotechnology 2003, 14, 824-828, https://doi.org/10.1088/0957-4484/14/7/323. 
29. Kumar S A.; Abyaneh, M.K.; Gosavi, S.W.; Kulkarni, S.K.; Pasricha, R.; Ahmad, A.; Khan, M.I. Nitrate reductase-mediated synthesis of silver nanoparticles from AgNO3. Biotechnology Letters 2007, 29, 439-445, https://doi.org/10.1007/s10529-006-9256-7.

30. Mukherjee, P.; Ahmad, A.; Mandal, D.; Senapati, S.; Sainkar, S.R.; Khan, M.I.; Ramani, R.; Parischa, R.; Ajayakumar, P.V.; Alam, M.; Sastry, M.; Kumar, R. Bioreduction of AuCl4- Ions by the Fungus, Verticillium sp. and Surface Trapping of the Gold Nanoparticles Formed. Angewandte Chemie International Edition 2001, 40, 3585-3588, https://doi.org/10.1002/1521-3773(20011001)40:19<3585::AIDANIE3585>3.0.CO;2-K.

31. Vigneshwaran, N.; Ashtaputre, N.M.; Varadarajan, P.V.; Nachane, R.P.; Paralikar, K.M.; Balasubramanya, R.H. Biological synthesis of silver nanoparticles using the fungus Aspergillus flavus. Materials Letters 2007, 61, 1413-1418, https://doi.org/10.1016/j.matlet.2006.07.042.

32. Bhainsa, K.C.; D'Souza, S.F. Extracellular biosynthesis of silver nanoparticles using the fungus Aspergillus fumigatus. Colloids and Surfaces B: Biointerfaces 2006, 47, 160-164, https://doi.org/10.1016/j.colsurfb.2005.11.026.

33. Balaji, D.S.; Basavaraja, S.; Deshpande, R.; Mahesh, D.B.; Prabhakar, B.K.; Venkataraman, A. Extracellular biosynthesis of functionalized silver nanoparticles by strains of Cladosporium cladosporioides fungus. Colloids and Surfaces B: Biointerfaces 2009, 68, 88-92, https://doi.org/10.1016/j.colsurfb.2008.09.022.

34. Madakka, M.; Jayaraju, N.; Rajesh, N. Mycosynthesis of silver nanoparticles and their characterization. MethodsX 2018, 5, 20-29, https://doi.org/10.1016/j.mex.2017.12.003.

35. Singh, D.; Rathod, V.; Ninganagouda, S.; Herimath, J.; Kulkarni, P. Biosynthesis of silver nanoparticle by endophytic fungi Pencillium sp. isolated from Curcuma longa (turmeric) and its antibacterial activity against pathogenic gram negative bacteria. Journal of Pharmacy Research 2013, 7, 448-453, https://doi.org/10.1016/j.jopr.2013.06.003.

36. Halkai, K.R.; Mudda, J.A.; Shivanna, V.; Rathod, V.; Halkai, R. Evaluation of Antibacterial Efficacy of Fungal-Derived Silver Nanoparticles against Enterococcus faecalis. Contemp Clin Dent 2018, 9, 45-48.

37. Soni N, Soam, P. Factors Affecting the Geometry of Silver Nanoparticles Synthesis in Chrysosporium Tropicum and Fusarium Oxysporum. Current Research in Nanotechnology 2012, 2, 112-121, https://doi.org/10.3844/ajnsp.2011.112.121.

38. Han, J.W.; Gurunathan, S.; Jeong, J.-K.; Choi, Y.-J.; Kwon, D.-N.; Park, J.-K.; Kim, J.-H. Oxidative stress mediated cytotoxicity of biologically synthesized silver nanoparticles in human lung epithelial adenocarcinoma cell line. Nanoscale Research Letters 2014, 9, https://doi.org/10.1186/1556-276X-9-459.

39. Siddiqi, K.S.; Husen, A.; Rao, R.A.K. A review on biosynthesis of silver nanoparticles and their biocidal properties. Journal of Nanobiotechnology 2018, 16, https://doi.org/10.1186/s12951-018-0334-5.

40. Afkhami, F.; Pourhashemi, S.J.; Sadegh, M.; Salehi, Y.; Fard, M.J.K. Antibiofilm efficacy of silver nanoparticles as a vehicle for calcium hydroxide medicament against Enterococcus faecalis. Journal of Dentistry 2015, 43, 1573-1579, https://doi.org/10.1016/j.jdent.2015.08.012.

41. Halkai, K.R.; Mudda, J.A.; Shivanna, V.; Rathod, V.; Halkai, R. Antibacterial Efficacy of Biosynthesized Silver Nanoparticles against Enterococcus faecalis Biofilm: An In vitro Study Contemp Clin Dent 2018, 9 , 237-241, https://doi.org/10.4103/ccd.ccd_828_17.

42. Halkai, K.; Halkai, R.; Mudda, J.; Shivanna, V.; Rathod, V. Antibiofilm efficacy of biosynthesized silver nanoparticles against endodontic-periodontal pathogens: An in vitro study. J Conserv Dent 2018, 21, 662666, https://doi.org/10.4103/JCD.JCD_203_18.

43. Shrestha, A.; Kishen, A. Antibacterial Nanoparticles in Endodontics: A\&\#xa0;Review. Journal of Endodontics 2016, 42, 1417-1426, https://doi.org/10.1016/j.joen.2016.05.021.

44. Lok, C.-N.; Ho, C.-M.; Chen, R.; He, Q.-Y.; Yu, W.-Y.; Sun, H.; Tam, P.K.-H.; Chiu, J.-F.; Che, C.-M. Proteomic Analysis of the Mode of Antibacterial Action of Silver Nanoparticles. Journal of Proteome Research 2006, 5, 916-924, https://doi.org/10.1021/pr0504079.

45. Yun, H.; Kim, J.D.; Choi, H.C.; Lee, C.W. Antibacterial Activity of CNT-Ag and GO-Ag Nanocomposites Against Gram-negative and Gram-positive Bacteria. Bulletin of the Korean Chemical Society 2013, 20, 3261-4, https://doi.org/10.5012/BKCS.2013.34.11.3261.

46. Iavicoli, I.; Fontana, L.; Leso, V.; Bergamaschi, A. The Effects of Nanomaterials as Endocrine Disruptors. International Journal of Molecular Sciences 2013, 14, 16732-16801, https://doi.org/10.3390/ijms140816732.

47. Liao, C.; Li, Y.; Tjong, S.C. Bactericidal and Cytotoxic Properties of Silver Nanoparticles. International Journal of Molecular Sciences 2019, 20, https://doi.org/10.3390/ijms20020449.

48. Kim, J.S.; Kuk, E.; Yu, K.N.; Kim, J.-H.; Park, S.J.; Lee, H.J.; Kim, S.H.; Park, Y.K.; Park, Y.H.; Hwang, C.-Y.; Kim, Y.-K.; Lee, Y.-S.; Jeong, D.H.; Cho, M.-H. Antimicrobial effects of silver nanoparticles. Nanomedicine: Nanotechnology, Biology and Medicine 2007, 3, 95-101, https://doi.org/10.1016/j.nano.2006.12.001.

49. Meikle, T.G.; Dyett, B.P.; Strachan, J.B.; White, J.; Drummond, C.J.; Conn, C.E. Preparation, Characterization, and Antimicrobial Activity of Cubosome Encapsulated Metal Nanocrystals. ACS Applied Materials \& Interfaces 2020, 12, 6944-6954, https://doi.org/10.1021/acsami.9b21783. 
50. Egger, S.; Lehmann, R.P.; Height, M.J.; Loessner, M.J.; Schuppler, M. Antimicrobial Properties of a Novel Silver-Silica Nanocomposite Material. Applied and Environmental Microbiology 2009, 75, 2973-76, https://doi.org/10.1128/aem.01658-08.

51. Noronha, V.T.; Paula, A.J.; Durán, G.; Galembeck, A.; Cogo-Müller, K.; Franz-Montan, M.; Durán, N. Silver nanoparticles in dentistry. Dental Materials 2017, 33, 1110-1126, https://doi.org/10.1016/j.dental.2017.07.002.

52. Morones-Ramirez, J.; Elechiguerra, J.; Camacho, A.; Holt, K.; Kouri, J.; Tapia, J.; Yacaman, M. The Bactericidal Effect of Silver Nanoparticles. Nanotechnology 2005, 16, 2346-2353,

53. Saravanan, M.; Arokiyaraj, S.; Lakshmi, T.; Pugazhendhi, A. Synthesis of silver nanoparticles from Phenerochaete chrysosporium (MTCC-787) and their antibacterial activity against human pathogenic bacteria. Microbial Pathogenesis 2018, 117, 68-72, https://doi.org/10.1016/j.micpath.2018.02.008.

54. Yin, I.X.; Yu, O.Y.; Zhao, I.S.; Mei, M.L.; Li, Q.-L.; Tang, J.; Chu, C.-H. Developing biocompatible silver nanoparticles using epigallocatechin gallate for dental use. Archives of Oral Biology 2019, 102, 106-112, https://doi.org/10.1016/j.archoralbio.2019.03.022.

55. Pugazhendhi, A.; Prabakar, D.; Jacob, J.M.; Karuppusamy, I.; Saratale, R.G. Synthesis and characterization of silver nanoparticles using Gelidium amansii and its antimicrobial property against various pathogenic bacteria. Microbial Pathogenesis 2018, 114, 41-45, https://doi.org/10.1016/j.micpath.2017.11.013.

56. Mozayeni, M.A.; Dianat, O.; Tahvildari, S.; Mozayani, M.; Paymanpour, P. Subcutaneous Reaction of Rat Tissues to Nanosilver Coated Gutta-Percha. Iran Endod J 2017, 12, 157-161, https://doi.org/10.22037/iej.2017.31.

57. Vazquez-Garcia, F.; Tanomaru-Filho, M.; Chávez-Andrade, G.M.; Bosso-Martelo, R.; Basso-Bernardi, M.I.; Guerreiro-Tanomaru, J.M. Effect of Silver Nanoparticles on Physicochemical and Antibacterial Properties of Calcium Silicate Cements. J Brazilian Dental Journal 2016, 27, 508-514, https://doi.org/10.1590/0103-6440201600689.

58. Dobias, J.; Bernier-Latmani, R. Silver Release from Silver Nanoparticles in Natural Waters. Environmental Science \& Technology 2013, 47, 4140-4146, https://doi.org/10.1021/es304023p.

59. Halkai, K.; Mudda, J.; Shivanna, V.; Patil, V.; Rathod, V.; Halkai, R. Cytotoxicity evaluation of fungalderived silver nanoparticles on human gingival fibroblast cell line: An in vitro study. Journal of Conservative Dentistry 2019, 22, 160-163, https://doi.org/10.4103/jcd.jcd_518_18. 